\title{
FATIGUE IN A COMPLEX FUNCTION
}

\author{
BY EDWARD L. THORNDIKE
}

Teachers College, Columbia Unibersity,

By the coöperation of eighty-nine students in a graduate course in educational psychology at Teachers College I am able to report measurements of the effect of about four hours of continuous work at writing poetry upon the quantity and quality of the product produced per unit of time and upon the satisfyingness of the process of producing it.

The work consisted of writing lines to complete 108 couplets, the first lines being given. These first lines were taken from Pope and Byron, the following being a random sampling.

Glittering with ice here hoary bills are seen

The fourth day rolled along and with the night

Self-love forsook the path it first pursued

What she has done no tears can wash away,

Bid harbors open, public ways extend

From the damp earth impervious vapors rise

Mark first that youth who takes the foremost place

Back to my native moderation slide

But still he only saw, and did not share,

In clouded majesty here dullness shone;

But while he shuns the grosser joys of sense,

But high above, more solid learning shone

They were arranged in 9 sets of 12 lines each (called hereafter sets $a, b, c, d, e, f, g, h$ and $i$ ). Eight sets were done 402 
without rest in the afternoon or evening of a given day; the ninth set being done after rest in the morning or afternoon of the following day. The individuals who engaged in the experiment were divided into nine squads (called hereafter squads $a b c, b c d$, cde, def, efg, fgh, ghi, hia and $i a b)$. One squad did the sets in the order $a, b, c, d, e, f, g, h$, rest, $i$; the next squad did the sets in the order $b, c, d, e, f, g, h, i$, rest, $a$; and so on. I shall use Period I, Period 2, Period 3, etc., to designate the nine periods of work. The arrangement of the work was then as in Table I.

Each individual recorded the time required to get the twelve couplets of each set, and also the degree of satisfyingness of the work on each set. The scale for satisfyingness was arbitrarily defined as follows: Call 5 the amount of enjoyment or satisfyingness of mental work which represents your average condition; let 10 represent the greatest amount

\section{TABLE I}

The Set of Couplets Coupleted by Each Squad in Each Period

\begin{tabular}{|c|c|c|c|c|c|c|c|c|}
\hline \multicolumn{9}{|c|}{ Period } \\
\hline $\mathbf{I}$ & 2 & 3 & 4 & 5 & 6 & 7 & 8 & 9 \\
\hline$a b c \ldots \ldots a$ & $b$ & $c$ & $d$ & $e$ & $f$ & $g$ & $h$ & $i$ \\
\hline$b c d \ldots \ldots b$ & $c$ & $d$ & $e$ & $f$ & g & $h$ & $i$ & $a$ \\
\hline$c d e \ldots \ldots \ldots$ & $d$ & $e$ & $f$ & g & $h$ & $i$ & $a$ & \\
\hline$d e f \ldots . . . d$ & $e$ & $f$ & $g$ & $h$ & $i$ & $a$ & $b$ & \\
\hline$<f g . \ldots \ldots \varepsilon$ & $f$ & $g$ & $h$ & $i$ & $a$ & $b$ & $c$ & $d$ \\
\hline$f_{g h} \ldots \ldots \ldots f$ & $g$ & $h$ & $i$ & $a$ & $b$ & $c$ & $d$ & e \\
\hline$g h i \ldots . . . g$ & $h$ & $i$ & $a$ & $b$ & $c$ & $d$ & $e$ & $f$ \\
\hline hia......h & $i$ & $a$ & $b$ & $c$ & $d$ & $e$ & $f$ & $g$ \\
\hline$i a b \ldots . \ldots i$ & $a$ & $b$ & $c$ & $d$ & $e$ & $f$ & $g$ & $h$ \\
\hline
\end{tabular}

of enjoyment or satisfyingness which you have experienced from mental work; let 0 represent the greatest distaste or intolerance toward any piece of work which you have experienced. Let $6,7,8,9$ and $1,2,3,4$ represent intermediate conditions by equal steps. This scale is obviously crude and unduly subjective, but will suffice for such inferences as will be drawn here.

The quality of the poetry written was measured as follows: The various completions of one couplet (call it $a$ I) were collated and graded by four judges. The same four judges 
would grade similarly the completions of another couplet (call it $a$ 2). A new combination of four judges would grade the completions of $a 3$ and $a 4$; a new combination would grade the completions of $a 5$ and $a 6$. In all about 80 judges shared in the work of grading the couplets for quality, each judge grading some hundred or more lines; and every line being graded by four judges. The grading was on a scale of 0 to IO, $O$ being a line absolutely devoid of merit and Io as good a line as, in the opinion of the judge, could be written to make that couplet. This again is obviously a very crude and unduly subjective scale, but will serve the purpose of the present argument sufficiently well.

We have then for each of eighty-nine individuals a record like the following of the time required for each of eight consecutively accomplished sets of 12 lines of poetry, and of one done the next day after rest, of the satisfyingness of the work at each of the nine periods, and of the quality of the product produced.

Individual M. D. F. did set $f$ in period $1,7.46 .30$ to 8.5.45 P.M., spending 25 minutes 15 seconds, the successive couplet-completions being rated as $16,17,21,15,14,17,17$, $9,6,13,13$ in quality by the sum of four judges' ratings. M. D. F. rated the satisfyingness of the work as 4 .

He did set $g$ in period 2, 8.8.45 to 8.29.30 P.M., spending 20 minutes 55 seconds, the successive couplet-completions being rated as $14,19,20,11,14,16,20,15,12,7,18,13$ in quality by the sum of four judges' ratings. M. D. F. rated the satisfyingness of the work as 4 .

And so on for the seven remaining sets.

These individual records are arranged in 9 squads so that each set $(a, b, c, d$, etc.) was done at each period, equalizing the effect of any differences in the difficulty of the sets of first lines to be made into couplets.

Examination of the individual records shows that for the problem under consideration there is no misleading in massing the results and presenting simply average or median achievements and degrees of satisfyingness by squads. 'This is done for time required, quality of product, and reported 
satisfyingness in Tables II., III. and IV., which utilize all the records for Period I, Period 8 (the last of the consecutive work-periods), and Period 9 (the work-period of the following day after rest). ${ }^{1}$

The facts are clear. The speed of work increases throughout the work-period and is not benefited by the rest. The average quality of the product produced falls off a very little, from 4.47 in Period $I$ to 4.24 in Period 8, and is slightly benefited by the rest, from 4.24 in Period 8 back to 4.47 in Period 9. The reported satisfyingness of the work falls off greatly, from 5.38 in Period 1 to 3.56 in Period 8, and is greatly benefited (from 3.56 to 4.85 ) by the rest. The effect of continuous exercises of the function is to increase gross efficiency, but to decrease satisfyingness or interest. The effect of the rest is a very slight gain in gross efficiency but a very great gain in satisfyingness or interest.

\section{TABLE II}

Times Required to Complete Sets of 12 Couplets at the Becinning of the Work-Period (Perjod I), at tye End of the Work-Perjod (Perjod 8), and on the Next Day After Rest (Period 9)

\begin{tabular}{|c|c|c|c|}
\hline Squad & Period I & Period 8 & Period 9 \\
\hline 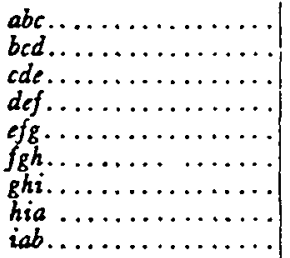 & $\begin{array}{l}29 \cdot 4 \\
37 \cdot 4 \\
39 \cdot 3 \\
35 \cdot 1 \\
44 \cdot 5 \\
36.4 \\
27 \cdot 7 \\
30.4 \\
30.0\end{array}$ & $\begin{array}{l}19.3 \\
20.7 \\
22.6 \\
23.3 \\
27.0 \\
24.6 \\
22.8 \\
28.3 \\
18.3\end{array}$ & $\begin{array}{l}21.7 \\
21.9 \\
22.4 \\
22.6 \\
.9 .7 \\
23.7 \\
25.3 \\
23.5 \\
17.8\end{array}$ \\
\hline Average......... & 34.5 & 23.0 & 23.2 \\
\hline
\end{tabular}

1 Some of the eighty-nine individuals did not complete all of the ro8 couplets within the approximate four hours set apart for the experiment. Some others by accident failed to complete the entire set of couplets or to score the time.

In all there were fourteen such individuals out of eighty-nine making 27 such blanks out of 801 . Where an individual did not do all eight sets in the work period the last set that he did do was treated as the set to be counted under Period 8 in Tables II., III. and IV. 


\section{TABLE III}

Median Qualtty of Poetry Written at tae Beginning of the Work-Period (Period 1), at the End of the Work-Period (Period 8), and on the Next Day After Rest (Period 9). The Quality Measure is The Sum of Ratings by Four Judges

\begin{tabular}{|c|c|c|c|}
\hline Squad & Period I & Period 8 & Period 9 \\
\hline 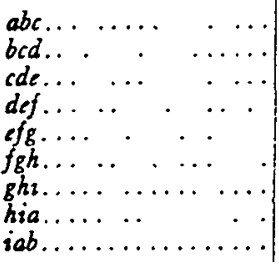 & $\begin{array}{l}15.5 \\
19.0 \\
18.5 \\
170 \\
18.5 \\
18.5 \\
20.0 \\
17.5 \\
16.5\end{array}$ & $\begin{array}{l}13.0 \\
17.0 \\
17.0 \\
18.5 \\
17.0 \\
16.5 \\
19.5 \\
17.0 \\
17.0\end{array}$ & $\begin{array}{l}14.5 \\
19.0 \\
18.0 \\
20.0 \\
17.0 \\
17.5 \\
19.5 \\
18.0 \\
17.5\end{array}$ \\
\hline Average quality & 4.47 & 4.24 & 4.47 \\
\hline
\end{tabular}

\section{TAble IV}

Reported Average Satisfyingness of Writing Poetry at the Beginning of the Work-Period (Period I), at the End of the Work-Period (Period 8), and on the Next Day After Rest (Peruod 9)

\begin{tabular}{|c|c|c|c|}
\hline Squad & Period I & Period 8 & Period 9 \\
\hline 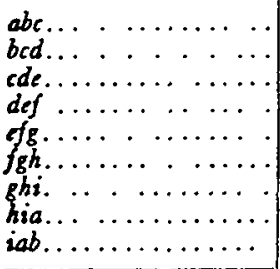 & $\begin{array}{l}4.75 \\
5.55 \\
5.30 \\
4.20 \\
5.09 \\
5.75 \\
6.50 \\
5.86 \\
5.43\end{array}$ & $\begin{array}{l}3.42 \\
4.89 \\
3.40 \\
3.70 \\
2.64 \\
3.52 \\
3.88 \\
2.71 \\
3.86\end{array}$ & $\begin{array}{l}4.42 \\
5.67 \\
4.90 \\
4.70 \\
3.91 \\
4.86 \\
5.38 \\
5.71 \\
4.14\end{array}$ \\
\hline Average. $\ldots \quad \ldots$ & 5.38 & 3.56 & 4.85 \\
\hline
\end{tabular}

\section{The Curve of Work}

The average amount per unit of time and satisfyingness reported for each successive period of the total work period and the quality of the product in periods $\mathrm{r}, 4,6$ and 8 , were as follows: ${ }^{1}$

1 The results given here are not for equal time periods but for successive sets of twelve of the couplets. Also there were necessary a few adjustments in the case of the $3 \frac{1}{2}$ per cent. of blank records referred to in a previous note. The average times of periods 1, 2, 3, 4, etc., were approximately $35,28,26,25,25,24,24$ and 23 minutes. 


\begin{tabular}{|c|c|c|c|c|c|c|c|c|}
\hline$\ldots \ldots \ldots$ & I & 2 & 3 & 4 & 5 & 6 & 7 & 8 \\
\hline $\begin{array}{l}\text { Couplets per ro minutes } \ldots \ldots \ldots \\
\text { Quality of couplets. } \ldots \ldots \ldots \ldots \ldots \ldots \\
\text { Satisfyingness................ }\end{array}$ & $\begin{array}{l}3.48 \\
4.47 \\
5.38\end{array}$ & \begin{tabular}{l}
4.36 \\
\hdashline .21
\end{tabular} & $\begin{array}{l}4.69 \\
\because .94\end{array}$ & $\begin{array}{l}4.82 \\
4.43 \\
4.48\end{array}$ & $\begin{array}{c}4.84 \\
\ldots \\
4.31\end{array}$ & $\begin{array}{l}5.08 \\
4.35 \\
3.95\end{array}$ & $\begin{array}{l}5.03 \\
3.67\end{array}$ & $\begin{array}{l}5.22 \\
4.24 \\
3.56\end{array}$ \\
\hline
\end{tabular}

The changes from period to period were thus:

\begin{tabular}{|c|c|c|c|c|c|c|c|}
\hline & $1-2$ & $2-3$ & $3-4$ & $4-5$ & $5-6$ & $6-7$ & $7-8$ \\
\hline $\begin{array}{l}\text { Couplets per } 10 \text { minutes } \ldots \ldots \\
\text { Satisfyingness... } \ldots .\end{array}$ & $\begin{array}{l}+.88 \\
-.19\end{array}$ & $\begin{array}{l}+.33 \\
-.27\end{array}$ & $\begin{array}{l}+.13 \\
-.46\end{array}$ & $\begin{array}{l}+.2 \\
-.17\end{array}$ & $\begin{array}{l}+.24 \\
-.36\end{array}$ & $\begin{array}{l}-.05 \\
-.28\end{array}$ & $\begin{array}{l}+.19 \\
-.11\end{array}$ \\
\hline Quality of couplets.. & \multicolumn{3}{|c|}{-.04 from 1 to 4} & \multicolumn{2}{|c|}{$\begin{array}{l}-.08 \text { from } \\
4 \text { to } 6\end{array}$} & \multicolumn{2}{|c|}{$\begin{array}{l}-.11 \text { from } \\
6 \text { to } 8\end{array}$} \\
\hline
\end{tabular}

These facts are also clear. Speed improves, with fluctuations such as one customarily finds. Quality remains about the same. Satisfyingness falls off throughout. 